This is the author's final, peer-reviewed manuscript as accepted for publication. The publisher-formatted version may be available through the publisher's web site or your institution's library.

\title{
Economic adjustments to groundwater depletion in the High Plains: do water-saving irrigation systems save water?
}

Jeffrey M. Peterson and Ya Ding

\section{How to cite this manuscript}

If you make reference to this version of the manuscript, use the following information:

Peterson, J. M., \& Ding, Y. (2005). Economic adjustments to groundwater depletion in the High Plains: Do water-saving irrigation systems save water? Retrieved from http://krex.ksu.edu

\section{Published Version Information}

Citation: Peterson, J. M., \& Ding, Y. (2005). Economic adjustments to groundwater depletion in the High Plains: Do water-saving irrigation systems save water? American Journal of Agricultural Economics, 87(1), 147-159.

Copyright: Copyright 2005 American Agricultural Economics Association

Digital Object Identifier (DOI): doi:10.1111/j.0002-9092.2005.00708.x

Publisher's Link: http://ajae.oxfordjournals.org/content/87/1/147.full

This item was retrieved from the K-State Research Exchange (K-REx), the institutional repository of Kansas State University. K-REx is available at http://krex.ksu.edu 
Economic Adjustments to Groundwater Depletion in the High Plains: Do Water-Saving Irrigation Systems Save Water?

\author{
Jeffrey M. Peterson \\ Ya Ding
}

March 2004

Send Correspondence to:

Jeffrey M. Peterson

Department of Agricultural Economics

331B Waters Hall

Kansas State University

Manhattan, KS 66506-4011

Phone: 785-532-4487

Fax: 785-532-6925

Email: jpeters@ksu.edu 


\section{ECONOMIC ADJUSTMENTS TO GROUNDWATER DEPLETION IN THE HIGH PLAINS: DO WATER-SAVING IRRIGATION SYSTEMS SAVE WATER? \\ JEFFREY M. PETERSON AND YA DING}

A common policy prescription for conserving irrigation water is to promote more efficient or “water-saving” irrigation technologies. We develop a risk programming model to quantify the effect of irrigation efficiency on irrigation water use in the High Plains, taking account of irrigation timing and well capacity limits. We find that optimal irrigation does not respond monotonically to changes in efficiency, although intermediate and high efficiency systems both result in less water use than an inefficient flood system.

Key words: irrigation efficiency, irrigation timing, High Plains, Ogallala aquifer, water conservation

Jeffrey M. Peterson is assistant professor and Ya Ding is graduate research assistant in the Department of Agricultural Economics, Kansas State University. The authors are grateful to Peter Berck and two anonymous reviewers for valuable comments. Funding for this research was provided by USDA-CSREES Special Grant IT 2002-06188. 


\section{ECONOMIC ADJUSTMENTS TO GROUNDWATER DEPLETION IN THE HIGH PLAINS: DO WATER-SAVING IRRIGATION SYSTEMS SAVE WATER?}

The High Plains is a semi-arid region encompassing much of the Texas and Oklahoma panhandles, eastern portions of New Mexico and Colorado, and western portions of Kansas and Nebraska. Although irrigated crop production in this region accounts directly for a small share of economic activity and employment, it is a primary pillar of the local economy. Extensive irrigation over the past several decades has generated substantial supplies of feedgrains and forages, which in turn have attracted a large number of cattle-feeding and meat processing operations to the region. Within the high plains, the meat processing sector is currently the primary driver of regional economic development and population growth.

By far the largest single source of irrigation water in the High Plains is the Ogallala Aquifer. Despite its status as the largest freshwater aquifer in the world, the Ogallala recharges very slowly and its available water volume has been steadily declining over the past three decades. Recent drought and the near exhaustion of the aquifer in some areas have prompted a renewed interest in regional policies to conserve groundwater (Peterson, Marsh, and Williams).

A common policy prescription for conserving irrigation water is to encourage the adoption of more efficient, or "water-saving” irrigation technologies that reduce evaporation and runoff losses (e.g., Johnson, Revenga, and Echeverria). An example of this type of policy was the recent extension of the Environmental Quality Incentives Program (EQIP) to cover water conservation improvements. As part of the 2002 Farm Act, EQIP funds were allocated to provide cost sharing to irrigators in selected states who invest in efficient irrigation systems.

Unfortunately, however, efficiency improvements do not always reduce overall water use. By definition, more efficient systems increase the share of gross irrigation (the quantity of water diverted) that becomes net irrigation (the quantity consumed by the crop, also known as 
consumptive use). Efficiency improvements therefore reduce the effective cost of net irrigation, and producers optimally respond to this cost change by increasing net irrigation, ceteris paribus (Whittlesey; Huffaker and Whittlesey 2003, 1995). In irrigated river basins, the change in net irrigation is the appropriate measure of water conservation, because much of the "lost" irrigation water is recaptured and returned to the watercourse. In regions irrigated from deep aquifers such as the Ogallala, on the other hand, conservation is frequently measured by changes in gross irrigation because the return flow to the aquifer is minimal and very slow. In this case, the conservation impact of an efficiency improvement is an empirical question: even if net irrigation increases, gross irrigation may change in either direction depending on the size of the net irrigation response. ${ }^{1}$

In developing empirical models to assess irrigation responses, researchers face several complications. First, irrigation differs from many other inputs because it can be dynamically adjusted as the growing season progresses. One approach to this issue in the literature is to solve for optimally timed irrigation events during the growing season. This is known as the irrigation scheduling problem, which several researchers have attacked with optimization methods including dynamic programming (e.g., Yaron et al., Bras and Cordova) and optimal control (Feinerman and Falkovitz). In these models, the irrigation decision at each point in time depends on the cost of irrigation compared to its benefits in terms of increased expected yield.

A second complication is the influence of risk-averting behavior on irrigation choices. To accurately model irrigation decisions in semi-arid regions such as the High Plains, timing and uncertainty issues are best modeled jointly, as the ability to adjust irrigation amounts as growing conditions evolve is viewed as a producer's primary tool for managing production risk. Rainfall in the High Plains is normally inadequate to obtain maximum crop yields and is highly variable 
within and across growing seasons. For a well of a given capacity, a more efficient system increases the amount of net irrigation that can reach the crop in periods of low rainfall. More efficient systems therefore lead to higher average yields as well as less variability in yields across years. Irrigators may adopt more efficient systems to protect the yields of water-intensive crops such as corn, which is highly sensitive to water stress during critical growth periods. This incentive is likely one of the factors that drove the rapid conversion from flood to center pivot systems in the High Plains in the 1990s (Peterson and Bernardo).

The objective of this paper is to analyze and quantify the effect of irrigation efficiency on groundwater conservation in the High Plains. We construct a mathematical programming model to compare irrigation systems with varying efficiency levels, taking account of irrigation timing, production risk and well capacity limits. Our empirical analysis is for irrigated corn production in western Kansas, representing the largest and fastest growing irrigated crop by acreage in this region over the past several years (Peterson and Bernardo). Data to estimate a Just-Pope production function for corn were generated from the Kansas Water Budget (KWB) model (Stone et al.), a daily-loop plant growth simulator designed for western Kansas conditions. The estimated production function is then incorporated in a two-moment risk programming model that solves for optimal irrigation schedules under observed rainfall patterns over several years, subject to well-capacity and authorized-use constraints. The two-moment approach to modeling decisions under uncertainty is based on the work of Just and Pope; Meyer; and Leathers and Quiggin.

To determine the impact of efficiency on groundwater conservation, we obtain optimal irrigation schedules for three irrigation systems with varying efficiencies (flood, center pivot sprinkler, and subsurface drip). In addition, we evaluate the long-run investments in these 
technologies by comparing the moments of the net return distributions under their respective optimal irrigation schedules. Comparisons are made under four combinations of well capacity and risk attitude. In all four cases, we find that gross irrigation does not respond monotonically to irrigation efficiency. Nevertheless, the more efficient systems (sprinkler and drip) always result in less gross irrigation than the inefficient flood system. Efficient systems also consistently increase yields and gross returns per acre, in large part because irrigation can be more effectively timed-more water can be delivered to the crop during episodic periods of low rainfall.

The remainder of the paper is organized as follows. The next section reviews and places our work in the context of the literature on irrigation investments and irrigated yield response. A third section introduces the two-moment decision model, which serves as the basis for the empirical analysis in the fourth section. The fifth and final section presents our conclusions and their policy implications.

\section{Previous Work}

Several studies have evaluated investments in new irrigation technologies (e.g., Caswell and Zilberman; Knapp; Letey et al). O’Brien et al. (2001a) reviewed studies on irrigation investment decisions specific to the High Plains. In all these investment models, an irrigator evaluates an investment in a new system by comparing investment and ownership costs to the increase in production net returns. The change in net returns results from reductions in production costs as well as increases in production revenue. Efficient systems may reduce production costs because fewer pumping hours are needed for a given amount of net irrigation, and also because operating expenses per hour may be smaller (Williams et al. 1997). Revenue will be affected if the new system increases crop yields. In general, the revenue impacts have received less attention in investment studies, presumably because they are more difficult to estimate than cost changes. ${ }^{2}$ 
In order to capture the changes in revenue, the yield responses to water must be quantified. Agricultural economists have typically accomplished this by estimating production functions of the form $f(w, z)$, which express crop yield as a function of total applied water during the season, $w$, and other nutrient inputs, $z$ (e.g., nitrogen). Although the most appropriate functional form for this relationship is still unresolved in the literature, a simple linear relationship is often statistically outperformed by more general functions.

The idea of a linear response is often attributed to von Liebig, who hypothesized that output "stands in direct relation” to whichever input is limiting (Paris, p. 1019). Subsequent researchers interpreted von Liebig’s hypothesis as being equivalent to a linear response and plateau (LRP) model, in which inputs are not substitutable and yield responds linearly to the limiting input until maximum yield is reached. Using a series of nonnested hypothesis tests, Frank, Beattie, and Embleton rejected the LRP model in favor of the Misterlich-Baule function, which has a concave surface and allows for input substitution. Paris pointed out that von Liebig's hypothesized "direct relation" does not need to be interpreted as a linear relation. Using the same data and testing procedures as Fank, Beattie, and Embleton, Paris showed that a nonlinear von Liebig model rejects all alternatives including the Misterlich-Baule. Berck and Helfand showed that even if the LRP model is the correct model for each plant, heterogeneity in soil and growing conditions imply that output for an entire land parcel will follow a smooth, concave function.

Agronomists, for their part, have typically modeled crop yield by characterizing the detailed biophysical processes related to plant growth. The response to water is captured indirectly through an intermediate variable known as evapotranspiration (ET), the combined amount of water transpired through the crop and evaporated from the soil surface (e.g., Stewart and Hagan). Yield is then specified as a function of ET, which in turn depends on water applied 
as well as other factors such as temperature and initial soil moisture. The quantitative relationships in these models are typically estimated from the large body of data obtained from agronomic experiments.

An important early contribution of these experiments was the finding that crop yields are more sensitive to changes in ET at certain times in the growing season or "stages of production" than at others (e.g., Shipley and Regier; Robins and Domingo). This led to modeling frameworks that explicitly account for different plant growth stages in the yield-ET relationship (e.g., Doorenbos and Kassam; Buller et al.). The Kansas Water Budget (KWB) model (Stone et al.) is typical of the recent generation of crop simulators. It computes ET on a daily cycle from daily observations of rainfall, irrigation, solar radiation, and temperature. Crop yield is then predicted from a function of four variables that represent accumulated daily ET in four stages of growth.

Our analysis in this article combines the approaches from agricultural economics and agronomy. A two-moment production function is estimated from data generated by the KWB simulator, where the inputs in the production function are specified as water applied during the four stages. This produces reduced-form relationships between stage-specific water inputs and the first two moments of the yield distribution. The remainder of the economic analysis can then proceed by abstracting from the biophysical details of production. The estimated relationship also captures the technical substitution or complementarity among water inputs during different stages of plant growth.

\section{Model Development}

Consider an irrigator's water-use decision on a single land parcel in a given year. To capture the effect of irrigation timing, let the growing season be divided into a finite number of plant growth stages, indexed by $i=1, \ldots, I$. The irrigator faces uncertainty in rainfall across years, which is 
represented by the discrete states of nature, $s=1, \ldots, S$; with probability $\gamma_{s}$, state $s$ is realized and the observed pattern of effective rainfall during the season is $\mathbf{r}_{s}=\left(r_{1 s}, \ldots, r_{I s}\right)$, where $r_{i s}$ is effective rainfall during stage $i$ in state $s .{ }^{3}$ Similarly, let $x_{i s}$ be the amount of gross irrigation applied during stage $i$ in state $s$. The seasonal pattern of gross irrigation in state $s$ is then $\mathbf{x}_{s}=\left(x_{1 s}\right.$, ..., $x_{I S}$ ), which we refer to as an irrigation schedule. From the rainfall and irrigation variables, the pattern of effective water in state $s$ can be constructed as $\mathbf{w}_{s}=\mathbf{r}_{s}+e \mathbf{x}_{s}$, where $e \in[0,1]$ represents irrigation efficiency. Although there are many definitions of irrigation efficiency, for our purposes $e$ is the fraction of gross irrigation that is not lost from evaporation or runoff and reaches the crop root zone. ${ }^{4}$

In addition to the risk from variation in rainfall across years, producers face another layer of uncertainty due to other uncontrollable factors within each growing season. Conditional on a realized pattern of rainfall $\mathbf{r}_{s}$ and an irrigation schedule $\mathbf{x}_{s}$, crop yield is still a random quantity because it depends on other random (and often unobserved) variables such as pest populations and site-specific variations in wind and humidity. We assume these within-season random factors can be captured by a Just-Pope production function, where yield in state $s$ obeys

$$
q_{s}=f\left(\mathbf{w}_{s}\right)+h\left(\mathbf{w}_{s}\right) \varepsilon_{s}, \quad E\left[\varepsilon_{s}\right]=0, \operatorname{Var}\left[\varepsilon_{s}\right]=1
$$

The functions $f\left(\mathbf{w}_{s}\right)$ and $h\left(\mathbf{w}_{s}\right)$ represent the effect of applied water on the mean and standard deviation of yield in state $s$, respectively (Just and Pope). $f\left(\mathbf{w}_{s}\right)$ is assumed to be increasing and concave in all its arguments, while the signs of its cross-partial derivatives depend on the technical complementarities or substitution among water inputs in different production stages. The shape of $h\left(\mathbf{w}_{s}\right)$ depends on the influence of water inputs on within-season production risk. If water in every stage is a risk-reducing input, for instance, then $h\left(\mathbf{w}_{s}\right)$ is decreasing in all its arguments. 
Profit in state $s$ is a random variable, which can be written

(2) $\quad \pi_{s}\left(\mathbf{x}_{s}\right)=p\left[f\left(\mathbf{r}_{s}+e \mathbf{x}_{s}\right)+h\left(\mathbf{r}_{s}+e \mathbf{x}_{s}\right) \varepsilon_{s}\right]-c(g, e) \sum_{i=1}^{I} x_{i s}-k(e)$

where $p$ is the output price, $c(g, e)$ represents marginal (i.e., per unit) pumping costs of gross irrigation, $g$ denotes well capacity, and $k(e)$ is other costs that include non-water production costs and the annualized investment cost of irrigation capital. Marginal pumping costs are assumed to decrease with well capacity $(\partial c / \partial g \leq 0)$ but may either increase or decrease with changes in efficiency ( $\partial c / \partial e$ may be of either sign). The response of cost to efficiency is an empirical question because some efficient systems require additional pressurization that consumes additional energy. For analytical convenience, we assume there are a large number of available technologies along a continuum of efficiency levels, so that $e$ can be treated as a continuous variable. This allows us to identify the impact of efficiency changes through comparative static analysis of differential changes in $e$. We also assume that higher efficiency systems require higher investment costs, so that $k^{\prime}(e) \geq 0$.

Conditional on state $s$, the only stochastic component in (2) is $\varepsilon_{s}$. The probability distribution of $\varepsilon_{s}$ induces a distribution of profit conditional on state $s$ and the irrigation schedule $\mathbf{x}_{s}$, denoted $\Phi_{\pi}\left(\pi ; s, \mathbf{x}_{s}\right)$, which has a mean and standard deviation of

$$
\begin{aligned}
& \text { (3) } \mu_{s}\left(\mathbf{x}_{s}\right)=p f\left(\mathbf{r}_{s}+e \mathbf{x}_{s}\right)-c(g, e) \sum_{i=1}^{I} x_{i s}-k(e) \\
& \text { (4) } \sigma_{s}\left(\mathbf{x}_{s}\right)=p h\left(\mathbf{r}_{s}+e \mathbf{x}_{s}\right)
\end{aligned}
$$

Irrigators seek to maximize the expected value of utility from profit:

$$
E[u(\pi)]=\sum_{s=1}^{S} \gamma_{s} \int u\left(\pi_{s}\left(\mathbf{x}_{s}\right)\right) d \Phi_{\pi},
$$

where $u(\pi)$ is a utility-of-income function. 
The integral in (5) is the conditional expected utility in state $s$. Given the structure of production risk in each state, conditional expected utility can be written as a function of the conditional mean and standard deviation in equations (3) and (4). Meyer showed that expected utility can be written as a function of the mean and standard deviation of income, provided that all income lotteries have distributions that differ only by location and scale. In our context, the location-scale property means that for any two irrigation schedules in state $s, \mathbf{x}_{s}^{0}$ and $\mathbf{x}_{s}^{1}$, $\Phi_{\pi}\left(\pi ; s, \mathbf{x}_{s}^{0}\right)=\Phi_{\pi}\left(\alpha+\beta \pi ; s, \mathbf{x}_{s}^{1}\right)$, where $\alpha$ and $\beta$ are real numbers. If this property holds, then there exists a function $V(\mu, \sigma)$ such that

$$
\int u\left(\pi_{s}\left(\mathbf{x}_{s}\right)\right) d \Phi_{\pi}=V\left(\mu_{s}\left(\mathbf{x}_{s}\right), \sigma_{s}\left(\mathbf{x}_{s}\right)\right) .
$$

Leathers and Quiggin showed that the location-scale property holds in the Just-Pope production model. The appendix demonstrates this result using our model notation. ${ }^{5}$

From equations (5) and (6), given a well capacity $g$ and current irrigation efficiency $e$, the irrigator's decision problem can be written

$$
\begin{aligned}
& \max _{\left\{\mathbf{x}_{1}, \ldots, \mathbf{x}_{s}\right\}} \sum_{s=1}^{S} \gamma_{s} V\left(\mu_{s}\left(\mathbf{x}_{s}\right), \sigma_{s}\left(\mathbf{x}_{s}\right)\right) \\
& \text { subject to: } 0 \leq \mathbf{x}_{s} \leq \mathbf{b}(g) \quad s=1, \ldots, S
\end{aligned}
$$

where $\mathbf{b}(g)$ is an $I \times 1$ vector of irrigation upper bounds $b_{i}(g), i=1, \ldots, I$, representing the maximum depths of irrigation that can be applied during each stage $i$ when the well pumping capacity is $g .{ }^{6}$ The producer's decision problem is to select a set of state-contingent irrigation schedules to maximize expected utility, subject to well capacity constraints. The solutions to (7) are a collection of vector functions, $\mathbf{x}_{s}\left(g, e, \mathbf{r}_{s}\right), s=1, \ldots, S$; each function represents the optimal irrigation schedule in a given state $s$ as a function of well capacity, efficiency, and the pattern of rainfall. 


\section{Long-run Decisions}

While the solutions $\mathbf{x}_{s}(\cdot)$ represent an irrigator's optimal short-run or within-season irrigation choices, they are also the data necessary to evaluate long-run decisions to invest in new irrigation technology. Analyzing the long-run decision allows us to assess the impact of investment subsidies on water conservation and producer welfare. Denote the maximized value of expected utility from problem (7) by $U(g, e) \equiv \sum_{s} \gamma_{s} V\left(\mu_{s}\left(\mathbf{x}_{s}\left(g, e, \mathbf{r}_{s}\right)\right), \sigma_{s}\left(\mathbf{x}_{s}\left(g, e, \mathbf{r}_{s}\right)\right)\right)$. An irrigator will make a long-run investment in a technology that increases irrigation efficiency from, say $e$ to $e^{\prime}$, if and only if

$$
U\left(g, e^{\prime}\right)>U(g, e)
$$

If this condition is initially violated, then the producer does not expect the benefits of the investment to outweigh its costs. If the investment costs in the more efficient technology are subsidized enough so that (8) is satisfied, however, the producer will invest in the new technology, with the result that irrigation efficiency and expected producer welfare are both increased.

Whether such programs reduce water use is a separate question. Insight on this question can be gained by considering the effect of a differential change in $e$ on the first order necessary condition for an optimal value of $x_{i s}$ from problem (7). Assuming an interior solution where $x_{i s}>$ 0 , this first-order condition is

$$
\gamma_{s} V_{\mu}\left(\mu_{s}, \sigma_{s}\right)\left[p f_{i}\left(\mathbf{r}_{s}+e \mathbf{x}_{s}\right) e-c(g, e)\right]+\gamma_{s} V_{\sigma}\left(\mu_{s}, \sigma_{s}\right) p h_{i}\left(\mathbf{r}_{s}+e \mathbf{x}_{s}\right) e-\lambda_{i s}=0
$$

where subscripts denote partial derivatives (e.g., $f_{i}(\cdot)=\partial f(\cdot) / \partial w_{i s}$ ), and $\lambda_{\text {is }}$ is the multiplier on the constraint $b_{i}(g)-x_{i s} \geq 0$. The complementary slackness condition for this constraint is $\lambda_{i s}\left[b_{i}(g)-\right.$ 
$\left.x_{i s}\right]=0$. If the constraint for $x_{i s}$ is strictly binding $\left(\lambda_{i s}>0\right.$ and $\left.x_{i s}=b_{i}(g)\right)$, then water use stays constant at the upper application limit for an differential change in $e$.

Therefore, $e$ affects water use only if the constraint is slack. In this situation, $\lambda_{i s}=0$ and (9) can be simplified to

$$
p f_{i}\left(\mathbf{r}_{s}+e \mathbf{x}_{s}\right) e-v\left(\mu_{s}, \sigma_{s}\right) p h_{i}\left(\mathbf{r}_{s}+e \mathbf{x}_{s}\right) e-c(g, e)=0
$$

where $v(\mu, \sigma) \equiv-V_{\sigma}(\mu, \sigma) / V_{\mu}(\mu, \sigma)$ is a measure of the irrigator's attitude toward risk. If $v(\mu, \sigma)$ $=0$ then the irrigator is risk neutral, while positive values indicate increasing risk aversion. To evaluate the impact of an efficiency change, consider a special case where: (a) the producer is risk neutral $(v(\mu, \sigma)=0)$, (b) the growing season consists of a single growth stage (implying the $i$ subscript can be dropped), and (c) efficiency changes do not affect marginal pumping costs $(\partial c / \partial e=0)$. Under these assumptions, optimal water use in state $s$ is the scalar-valued function $x_{s}\left(g, e, r_{s}\right)$, where $r_{s}$ is rainfall during the single stage of growth. Optimal water use is implicitly defined by the first order condition

$$
p f^{\prime}\left(r_{s}+e x_{s}\left(g, e, r_{s}\right)\right) e-c(g, e)=0 \text {. }
$$

Differentiating (11) with respect to $e$ and rearranging,

$$
\frac{\partial x_{s}}{\partial e}=\frac{-f^{\prime}\left(r_{s}+e x_{s}\right)}{f^{\prime \prime}\left(r_{s}+e x_{s}\right) e^{2}}-\frac{x_{s}}{e}
$$

The first term on the right side of (12) is positive because both its numerator and denominator are negative (under the assumptions $f^{\prime}(\cdot)>0$ and $f^{\prime \prime}(\cdot)<0$ ). The second term, $x_{s} / e$, is the ratio of two positive values. $\partial x_{s} / \partial e$ is therefore indeterminate in sign because it is the difference of two positive numbers whose magnitudes depend on the shape of the production function.

Thus, even under several simplifying assumptions, the effect of an efficiency change on water use is ambiguous. Relaxing any of these assumptions would introduce further ambiguities 
because the comparative static analysis in (12) would include additional terms involving the derivatives of $h(\cdot), v(\cdot)$ and $c(\cdot)$. These results suggest that efficiency changes may impact water use differently in different situations, and that empirical analysis is required to determine the impacts. Such an analysis is the subject of the next section.

\section{Empirical Application to Corn Production on the Kansas High Plains}

We apply the model above to irrigated corn production in western Kansas. Irrigated corn acreage in western Kansas more than doubled between the mid 1980s and 2000 and now accounts for about 53\% of irrigated land area in the region. It is regarded as the crop of choice among Kansas irrigators, most likely due to varietal improvements over the past 20 years that have dramatically raised corn yields relative to competing crops (Peterson and Bernardo).

\section{Data and Estimation}

Yield data to estimate a Just-Pope production function were generated from the KWB model. The dataset contained four independent variables $\left(w_{i}, i=1, \ldots, 4\right)$, each of which represents total effective water (i.e., effective rainfall plus net irrigation) applied during different stages of growth. The stages are defined as: (1) preplant from April 1 to May 16 (46 days), (2) vegetative from May 17 to July 15 (60 days), (3) flowering from July 16 to August 4 (20 days), and (4) ripening from August 5 to September 23 (50 days). 240 values of $\mathbf{w}=\left(w_{1}, w_{2}, w_{3}, w_{4}\right)$ were constructed using sixteen years of rainfall data from Tribune, Kansas (1985-2000) and fifteen randomly generated irrigation patterns. The KWB model was run for each of these combinations to generate a predicted corn yield. In addition to applied water, the KWB model requires inputs of daily minimum and maximum temperatures and solar radiation; these variables were set to the observed values at Tribune for the year corresponding to the rainfall data. 
Because irrigation scheduling and investment decisions depend on the shapes of both the mean-of-output and the variance-of-output functions, the flexible translog form was specified for both functions to minimize the number of a priori restrictions on these relationships. Thus, both $f(\mathbf{w})$ and $h(\mathbf{w})$ take the general form

$$
y=\beta_{0}+\sum_{i=1}^{4} \beta_{i} \ln w_{i}+\frac{1}{2} \sum_{i=1}^{4} \sum_{j=1}^{4} \delta_{i j} \ln w_{i} \ln w_{j}+\xi,
$$

where $y$ is the dependent variable (either the mean or standard deviation of yield), $\delta_{i j}=\delta_{j i}$, and $\xi$ is a random disturbance term.

The translog model was estimated using the three-stage procedure described by Just and Pope. The final specification and estimation results are in table 1 . The goodness of fit is much higher for the mean equation than the standard deviation equation, with adjusted R-squares of 0.89 and 0.08 , respectively. The latter suggests that variations in water inputs explain a relatively small share of the deviations in yield around its mean; i.e., the uncertainty in yield arises from several other factors besides water use. Nevertheless, the t-ratios in the standard deviation equation imply we can have confidence in the individual coefficients.

To aid in interpretation, table 2 reports the response elasticities of water at each growth stage in both equations. In computing the elasticities at the minimum and maximum values each variable, other variables were held at their mean values. Expected yield is most responsive to water in the preplant and flowering stages at low levels of application (elasticities at minimum water values are $\eta=0.467$ and $\eta=0.409$ in these two stages, respectively). In both these stages, the response rate declines as additional water is applied. In the vegetative stage, the expected yield elasticity is negative, albeit small $(\eta=-0.052)$, at low levels of application. This result may arise because water stress early in the season encourages deeper rooting that increases the response to water in later stages. Thus, holding water applications at other stages constant at their 
mean values, more water in the vegetative stage may reduce yields in a dry year. The expected yield elasticity with respect to water in the ripening stage is constant and relatively small ( $\eta=$ 0.033).

Perhaps contrary to expectations, the standard deviation elasticities suggest that water is not a risk-reducing input in all growth stages. Yield variability increases with water use during the "early" stages (the standard deviation elasticities in the preplant and vegetative stages are 0.092 and 0.592 , respectively). This result may also be related to plant root depth, since shallow roots from additional early water will expose the producer to more risk. In the flowering stage, the marginal effect of water on risk depends on how much water is applied. At low levels of application, the marginal unit of water substantially increases yield variability $(\eta=2.624)$, while water reduces risk at the margin at larger application levels. Water during the ripening stage reduces risk at all application levels $(\eta=-0.07)$. The different impacts on risk across stages of production may explain some of the conflicting results in previous empirical studies, where water was found to be risk-increasing in some cases and risk-reducing in others. ${ }^{7}$

\section{Optimal Irrigation Schedules}

Optimal irrigation schedules were computed based on the yield functions in table 1 and the twomoment expected utility function

$$
V(\mu, \sigma)=\mu-\frac{a}{2} \sigma^{2}
$$

where $a$ is the Arrow-Pratt coefficient of absolute risk aversion. This function is an exact representation of expected utility when returns are normally distributed and utility is of the form $u(\pi)=-e^{-a \pi}$. More generally, it can be regarded as a first order approximation to unknown risk preferences, where different levels of risk aversion can be explored by varying $a$. 
Table 3 shows the levels of $a$ and other model parameters. The values for $a$ reflect the range of risk aversion levels for per-acre returns suggested by empirical evidence (Kramer and Pope, 1981, 1986; Grube). The two well flow rates are typical of low-capacity systems in the Kansas High Plains (O’Brien et al., 2001a). Non-water costs of production and costs of irrigation capital are based on Kansas State University Extension budgets and a survey of irrigation equipment dealers (Dumler et al., 2001a, 2001b; O’Brien et al., 2001b). The annualized costs of capital assume a usable life of 20, 20, and 15 years, for the flood, sprinkler, and subsurface systems, respectively. All three systems are assumed to irrigate a 160-acre square field. Because the center pivot system only irrigates a 126-acre circle within the field, the non-water costs of production were adjusted by the amount of returns from a wheat-fallow rotation on the nonirrigated “corners” (O’Brien et al., 1998).

Constrained optimal irrigation schedules were computed by solving the nonlinear programming problem defined in equation (7), where the weather conditions from 1985-2000 were regarded as the states of nature. ${ }^{8}$ Pumping $\operatorname{costs} c(g, e)$ were estimated using the Irrigation Economics Evaluation System software developed by Williams et al. (1996). The upper limits for irrigation $b_{i}(g)$ were found from standard engineering formulas that relate well capacities in gallons per minute to maximum application rates in acre-inches per acre for a given irrigated area. In addition to the constraints for each growth stage, the annual pumping volume was also constrained not to exceed 24 inches, a typical authorized use on a groundwater right in western Kansas. $^{9}$

The top portion of table 4 shows the constraint limits for each growth stage (due to the well capacity) and for the season (due to the water right). Note that the capacity limits are larger for sprinkler irrigation than for flood or drip because the same amount of pumped water would 
be spread over 126 acres instead of 160 . The middle and bottom sections of table 4 show the optimal irrigation schedules under risk neutrality and risk aversion, reported as the average of the model solutions over the sixteen states of nature. At 300 gpm, these average optimal irrigation amounts nearly coincide with the well capacity limits for all stages except preplant, while total seasonal irrigation is always below authorized use. At $500 \mathrm{gpm}$, on the other hand, seasonal irrigation is at or near the authorized quantity and the capacity constraints are only binding in certain cases. These results illustrate the fact that irrigators with low-capacity systems are constrained primarily access to water rather than the legal right to consume it.

As discussed above, water is a risk decreasing input in some growth stages and a risk increasing input in others (table 2). Thus, risk aversion may affect the seasonal total of irrigation water use in either direction. As shown in table 4, risk-averse producers would apply less water for the season compared to their risk neutral counterparts, although the average difference is less than $6 \%$. Preplant and vegetative irrigation is reduced under risk aversion, since water in these stages increases yield variability.

\section{Effects of Irrigation Efficiency}

Converting to systems with a higher irrigation efficiency may affect water use, crop yield, and irrigator welfare. To evaluate the water use effects, we construct three distinct but related measures. Let $X_{s}$ and $W_{s}$ denote (per-acre) total seasonal gross irrigation and effective water in state $s$, defined as $X_{s}=\sum_{i} X_{i s}$ and $W_{s}=\sum_{i} w_{i s}$, respectively. ${ }^{10}$ The long-run average values of total seasonal irrigation and effective water can then be computed as $\bar{X}=\sum_{s} S^{-1} X_{s}$ and $\bar{W}=\sum_{s} S^{-1} W_{s}$, respectively, where each state of nature in the empirical distribution is assumed to occur with equal probability. The quantity of greatest interest for groundwater conservation is 
total volume pumped from a given well. Here, this quantity is measured by $A \bar{X}$, where $A$ is the number irrigated acres in the field (126 acres for center pivot and 160 acres for flood and subsurface systems).

These three water-use measures are in the first three rows of each panel in table 5. The effect of efficiency improvements of water use depends on which measure is selected. In all four combinations of risk aversion and well capacity levels, more efficient systems increase total seasonal effective water $(\bar{W})$. Averaging across the four cases, the sprinkler and subsurface systems deliver $17 \%$ and $27 \%$ more water to the crop root zone than the flood system, respectively. Total seasonal irrigation per acre $(\bar{X})$ does not respond monotonically to efficiency, as it is generally highest for the intermediate-efficiency sprinkler system. Interestingly, volume pumped ( $A \bar{X}$ ) is also non-monotonic but exhibits nearly the reverse pattern of irrigation itself. Both the sprinkler and subsurface systems reduce total seasonal irrigation-whether measured per acre or by total volume-compared to the flood system. Because the sprinkler system irrigates fewer acres it results in the smallest pumping volume, even though irrigation per acre is minimized with the subsurface system.

Crop yields uniformly increase with efficiency improvements even in the cases where total seasonal irrigation declines. For example, with a 300gpm well under risk neutrality, converting from flood to a subsurface drip system would increase yield from 118 to 150 bushels per acre (a 27\% increase). This yield increase will be obtained even though total seasonal irrigation would decline by an average of about one inch per acre. Higher yields could be obtained both because more water reaches the crop over the whole season (on average, 27 inches instead of 21.4) and because irrigation water can be distributed more effectively within seasons. 
The timing effects cannot be captured with standard models that relate output to the seasonal total of inputs.

An irrigators' welfare is measured by long-run expected utility. From equation (14), this can be computed as

$$
U(g, e)=\sum_{s=1}^{S} \frac{1}{S} \mu_{s}\left(\mathbf{x}_{s}\left(g, e, \mathbf{r}_{s}\right)\right)-\frac{a}{2} \sum_{s=1}^{S} \frac{1}{S} \sigma_{s}^{2}\left(\mathbf{x}_{s}\left(g, e, \mathbf{r}_{s}\right)\right)
$$

The components of equation (15) are also in table 5. In all cases considered, the subsurface system maximizes both mean yield and the returns to capital and management. The results suggest that irrigators would benefit from high efficiency systems primarily through increased crop yields. Previous research has noted the potential for more efficient systems to reduce the cost of delivering water to the crop. However, in all the cases analyzed here, irrigators with more efficient systems would optimally incur higher pumping costs, which are more than offset by additional revenue from higher yields per acre.

While subsurface systems maximize returns to land and capital, the additional returns do not outweigh the larger investment costs. Expected utility of net returns is maximized with the sprinkler system in all cases, but this result is naturally sensitive to the assumed cost of the subsurface system. The subsurface system would become the optimal choice in all cases considered if its cost were reduced by $30 \%$ (for instance, through government cost share programs). In a budget analysis of alternative irrigation systems, O’Brien et al. (1998) also found that the subsurface system was not cost-effective for typical irrigation settings in the High Plains. However, they noted that subsurface irrigation has an advantage for small or irregular field sizes, since the large fixed investment needed for a sprinkler system creates a prohibitive fixed cost per acre in small fields. 


\section{Conclusions and Implications}

Cost-share programs for irrigation investments are often cited as a possible strategy for conserving groundwater. These policies may not have the desired effect in general; an increase in irrigation efficiency may either increase or decrease gross irrigation depending on production relationships. However, our empirical results suggest that such incentive programs would reduce irrigation water use for corn production in the Kansas High Plains. Converting from flood to a subsurface drip system would decrease both irrigation per acre and the volume of groundwater withdrawn. The conversion from flood to center pivot would increase irrigation per acre but decrease the volume pumped because fewer acres would be irrigated.

Our analysis explicitly considered the effects of irrigation timing and production risk. Timing effects were found to be important overall and led to "unexpected" relationships between crop outputs and irrigation inputs. Higher yields were obtained with fewer inches of total irrigation because irrigation water is more effectively distributed throughout the season. Our results also reflect the importance of production risk in semi-arid High Plains: across the cases analyzed, the standard deviation of net returns was between $50 \%$ and $155 \%$ of the mean returns to land and capital. Despite the importance of risk itself, the water-use predictions of the model were quite robust to the assumption that irrigators are risk-averse. Optimal irrigation schedules for a risk-averse decision maker differ from the risk-neutral case by less than $10 \%$. This result is consistent with Pannell, Malcom, and Kingwell's assertion that risk aversion generally has a small impact on continuous input choices (such as irrigation amounts), because the expected utility function is relatively "flat" in the neighborhood of an optimal input strategy. However, risk aversion generally has a greater impact on discrete decisions such as investments in new irrigation technologies. 
For irrigators, high efficiency systems are a potentially effective way of counteracting groundwater depletion. The conversion from flood to center pivot was found to be cost-effective for all cases considered, and the benefit of this conversion was largest for a low well capacity. This finding is consistent with the recent investment trends in western Kansas, where more than half of flood-irrigated acreage in 1991 had been converted to center pivot systems by 2000 (Peterson and Bernardo). The subsurface drip system consistently generated the largest return to land and capital, but the additional returns were not large enough to outweigh its substantial ownership cost. However, a cost-share program that reduced subsurface drip installation costs by $30 \%$ would make it the farmer's optimal choice in all cases. Our results therefore lend some support to the idea that such a cost share program would serve the dual objectives of groundwater conservation and improving irrigators’ welfare. 


\section{Appendix: Verification of the Location-Scale Property}

The location-scale property of the profit distribution can be verified as follows. Equations (3) and (4) imply that profit in state $s$ (defined in equation (2)) may be equivalently written

$$
\pi_{s}\left(\mathbf{x}_{s}\right)=\mu_{s}\left(\mathbf{x}_{s}\right)+\sigma_{s}\left(\mathbf{x}_{s}\right) \varepsilon_{s} .
$$

By definition, the cumulative distribution function (cdf)of profit in state $s$ is

$$
\Phi_{\pi}\left(\pi ; s, \mathbf{x}_{s}\right) \equiv \operatorname{Pr}\left\{\pi_{s}(\mathbf{x}) \leq \pi\right\} .
$$

Substituting equation (16) into this definition and rearranging, we have

$$
\begin{aligned}
\Phi_{\pi}\left(\pi ; s, \mathbf{x}_{s}\right) & =\operatorname{Pr}\left\{\varepsilon \leq \frac{\pi-\mu_{s}\left(\mathbf{x}_{s}\right)}{\sigma_{s}\left(\mathbf{x}_{s}\right)}\right\} \\
& =\Phi_{\varepsilon}\left(\frac{\pi-\mu_{s}\left(\mathbf{x}_{s}\right)}{\sigma_{s}\left(\mathbf{x}_{s}\right)} ; s\right),
\end{aligned}
$$

where $\Phi_{\varepsilon}(\tilde{\varepsilon} ; s) \equiv \operatorname{Pr}\left\{\varepsilon_{s} \leq \tilde{\varepsilon}\right\}$ denotes the cdf of $\varepsilon_{s}$. The location-scale property is satisfied if there exist real constants $\alpha$ and $\beta$ such that $\Phi_{\pi}\left(\pi ; s, \mathbf{x}_{s}^{0}\right)=\Phi_{\pi}\left(\alpha+\beta \pi ; s, \mathbf{x}_{s}^{1}\right)$ for arbitrary irrigation schedules $\mathbf{x}_{s}^{0}$ and $\mathbf{x}_{s}^{1}$. The values $\alpha=\mu_{s}\left(\mathbf{x}_{s}^{1}\right)-\mu_{s}\left(\mathbf{x}_{s}^{0}\right)\left[\sigma_{s}\left(\mathbf{x}_{s}^{1}\right) / \sigma_{s}\left(\mathbf{x}_{s}^{1}\right)\right]$ and $\beta=\sigma_{s}\left(\mathbf{x}_{s}^{1}\right) / \sigma_{s}\left(\mathbf{x}_{s}^{0}\right)$ satisfy this requirement, since

$$
\begin{aligned}
\Phi_{\pi}\left(\alpha+\beta \pi ; s, \mathbf{x}_{s}^{1}\right) & =\operatorname{Pr}\left\{\varepsilon \leq \frac{\alpha+\beta \pi-\mu_{s}\left(\mathbf{x}_{s}^{1}\right)}{\sigma_{s}\left(\mathbf{x}_{s}^{1}\right)}\right\} \\
& =\operatorname{Pr}\left\{\varepsilon \leq \frac{\mu_{s}\left(\mathbf{x}_{s}^{1}\right)-\mu_{s}\left(\mathbf{x}_{s}^{0}\right)\left[\sigma_{s}\left(\mathbf{x}_{s}^{1}\right) / \sigma_{s}\left(\mathbf{x}_{s}^{0}\right)\right]+\left[\sigma_{s}\left(\mathbf{x}_{s}^{1}\right) / \sigma_{s}\left(\mathbf{x}_{s}^{0}\right)\right] \pi-\mu_{s}\left(\mathbf{x}_{s}^{1}\right)}{\sigma_{s}\left(\mathbf{x}_{s}^{1}\right)}\right\} \\
& =\operatorname{Pr}\left\{\varepsilon \leq\left[\frac{\pi-\mu_{s}\left(\mathbf{x}_{s}^{0}\right)}{\sigma_{s}\left(\mathbf{x}_{s}^{0}\right)}\right]\right\} \\
& =\Phi_{\pi}\left(\pi ; s, \mathbf{x}_{s}^{0}\right)
\end{aligned}
$$




\section{Footnotes}

${ }^{1}$ A simple example can illustrate this result. Suppose irrigation efficiency is initially 50\%, and that net and gross irrigation are 100 and 200 acre-feet, respectively. Suppose also that a new irrigation system would increase efficiency to 75\%. If the irrigator adopts this system and increases net irrigation by a "small” amount, to 120 acre-feet, then gross irrigation will decrease to 160 acre-feet. But if the net irrigation response is "large," to 180 acre-feet, then gross irrigation will increase to 240 acre-feet.

${ }^{2}$ Irrigation costs are now well understood from engineering research and can be accurately predicted for most irrigation systems (Williams et al., 1996).

${ }^{3}$ Effective rainfall is defined as the amount of rainfall that is not lost to runoff and reaches the crop root zone.

${ }^{4}$ The definitions of effective rainfall and irrigation efficiency imply that $\mathbf{w}_{s}$ represents the water that will either become ET or be lost as percolation below the root zone. These definitions are chosen to be consistent with the KWB simulator, which updates the water balance in the root zone using rain and irrigation water as exogenous inputs and computes both ET and percolation.

${ }^{5}$ This two-moment approach is one of several ways to model choices under risk. It is particularly advantageous in a nested framework such as ours. As explained more fully below, the long-run decision problem to invest in new technology can be easily constructed from the short-run problem to schedule irrigation events.

${ }^{6}$ For example, a 300 gallon-per-minute well that irrigates a 160-acre field can supply at most 0.1 inches of gross irrigation water per day, or 1 inch during a 10-day growth period.

${ }^{7}$ The authors are grateful to an anonymous reviewer for making this observation. 
${ }^{8}$ Although the model variables $r_{i s}$ conceptually represent effective rainfall, our only available data is for total rainfall. This assumes that runoff losses are negligible and can be treated as zero, and may lead to a downward bias in predicted irrigation amounts. The magnitude of the error would be relatively small for a flat land parcel with a coarsely textured soil.

${ }^{9}$ Every groundwater irrigator in Kansas is required to hold a water right and to submit an annual water use report for each point of withdrawal. As of 2001, about half of all groundwater reports in western Kansas were based on readings from meters installed at the well. In modeling water rights as a constraint, we assume that irrigators are sufficiently averse to the penalties for exceeding their authorized use.

${ }^{10}$ Although $X_{s}$ and $W_{s}$ are related by the equations $w_{i s}=r_{i s}+e x_{i s}(i=1, \ldots, 4)$, they may not respond in the same direction from a change in $e$. To illustrate, suppose an increase in $e$ leads to a reduction in $x_{i s}$. The new value of $w_{i s}$ then depends on $r_{i s}$ and the product of the new values of $e$ and $x_{i s}$; the change in $w_{i s}$ is therefore indeterminate and depends on the relative magnitudes of the changes in $e$ and $x_{i s}$. See footnote 1 for a numerical example. 


\section{References}

Berck, P., and G. Helfand. "Reconciling the von Liebig and Differentiable Crop Production Functions.” American Journal of Agricultural Economics 72(1990):985-96.

Bras, R.L., and J.R. Cordova. “Intraseasonal Water Allocation in Deficit Irrigation.” Water Resources Research 17(1981):866-74.

Buller, O., H.L. Manges, L.R. Stone, and J.R. Williams. “Modeled Crop Water Use and Soil Water Drainage.” Agricultural Water Management 19(1991):117-34.

Caswell, M., and D. Zilberman. “The Effects of Well Depth and Land Quality on the Choice of Irrigation Technology.” American Journal of Agricultural Economics 68(1986):798-811.

Doorenboos, J., and A.S. Kassam. “Yield Response to Water.” Irrigation and Drainage Paper No. 33, Food and Agricultural Organization of the United Nations, Rome, 1979.

Dumler, T.J., C.R. Thompson, D.M. O’Brien, and R. Stockton. “Center-Pivot-Irrigated Corn Cost-Return Budget.” Publication MF-585, Kansas State University Agricultural Experiment Station and Cooperative Extension Service, October 2001a.

—_. "Flood-Irrigated Corn Cost-Return Budget.” Publication MF-578, Kansas State University Agricultural Experiment Station and Cooperative Extension Service, October 2001b.

Feinerman, E., and M.S. Falkovitz. “Optimal Scheduling of Nitrogen Fertilization and Irrigation.” Water Resources Management 11(1997):101-17.

Frank, M.D., B.R. Beattie, and M.E. Embleton. “A Comparison of Alternative Crop Response Models.” American Journal of Agricultural Economics 72(1990):597-603.

Grube, A.H. "Participation in Farm Commodity Programs: A Stochastic Dominance Analysis: Comment.” American Journal of Agricultural Economics 68(1986):185-88. 
Huffaker, R., and N. Whittlesey. “A Theoretical Analysis of Economic Incentive Policies Encouraging Agricultural Water Conservation.” International Journal of Water Resources Development 19(2003):37-53.

Huffaker, R., and N. Whittlesey. “Agricultural Water Conservation Legislation: Will it Save Water?” Choices 4(1995):24-28.

Johnson, N., C. Revenga, and J. Echeverria. “Managing Water for People and Nature.” Science 292(2001):1071-72.

Just, R.E., and R.D. Pope. "Production Function Estimation and Related Risk Considerations.” American Journal of Agricultural Economics 61(1979):276-84.

Knapp, K.C. “Irrigation Management and Investment Under Saline, Limited Drainage Conditions: 2. Characterization of Optimal Decision Rules.” Water Resources Research 28(1992):3091-97.

Kramer, R.A., and R.D. Pope. "Participation in Farm Commodity Programs: A Stochastic Dominance Analysis.” American Journal of Agricultural Economics 63(1981): 119-28.

—_. "Participation in Farm Commodity Programs: A Stochastic Dominance Analysis: Reply." American Journal of Agricultural Economics 68(1986):189-90.

Leathers, H.D., and J.C. Quiggin. “Interactions between Agricultural and Resource Policy: The Importance of Attitudes Toward Risk.” American Journal of Agricultural Economics 73(1991):757-64.

Letey, J., A. Dinar, C. Woodring, and J.D. Oster. “An Economic Analysis of Irrigation Systems.” Irrigation Science 11(1990):37-43.

Meyer, J. “Two-Moment Decision Models and Expected Utility Maximization.” American Economic Review 77(1987):421-30. 
O’Brien, D.M., F.R. Lamm, L.R. Stone, and D.H. Rogers. “Corn-Yield and Profitability for Low-Capacity Irrigation Systems.” Applied Engineering in Agriculture 17(2001a):31521.

O’Brien, D.M., R. Stockton, T.J. Dumler, and C.R. Thompson. "Wheat Cost-Return Budget in Western Kansas.” Publication MF-903, Kansas State University Agricultural Experiment Station and Cooperative Extension Service, October 2001b.

O’Brien, D.M., D.H. Rogers, F.R. Lamm, and G.A. Clark. “An Economic Comparison of Subsurface Drip and Center Pivot Sprinkler Irrigation Systems.” Applied Engineering in Agriculture 14(1998):391-98.

Pannell, D.J., B. Malcolm, and R.S. Kingwell. “Are We Risking Too Much? Perspectives on Risk in Farm Modelling.” Agricultural Economics 23(2000):69-78.

Paris, Q. “The von Liebig Hypothesis.” American Journal of Agricultural Economics 74(1992):1020-28.

Peterson, J.M., and D.J. Bernardo. “High Plains Regional Aquifer Study Revisited: A 20-Year Retrospective for Western Kansas.” Great Plains Research 13(2003):179-97.

Peterson, J.M., T.L. Marsh, and J.R. Williams. "Conserving the Ogallala Aquifer: Efficiency, Equity, and Moral Motives.” Choices 1(2003):15-18.

Robins, J.S., and C.E. Domingo. "Some Effects of Severe Soil Moisture Deficits at Specific Growth Stages in Corn.” Agronomy Journal 45(1953):618-21.

Shipley, J., and C. Regier. “Corn Yield Response to Limited Irrigations, High Plains of Texas.” Texas Agricultural Experiment Station Progress Report 3379C, Texas A\&M University, College Station Texas, 1976. 
Stewart, J.I., and R.M. Hagan. "Functions to Predict Effects of Crop Water Deficits." Journal of the Irrigation Drainage Division 99(1973):421-39.

Stone, L.R., O.H. Buller, A.J. Schlegel, M.C. Knapp, J.Perng, A.H. Khan, H.L. Manges, and D.H. Rogers. Description and Use of Kansas Water Budget: Version T1 Software. Department of Agronomy, Kansas State University, Manhattan, Kansas, 1995.

Whittlesey, N.K. "Improving Irrigation Efficiency through Technology Adoption: When Will it Conserve Water?” Water Resources Perspectives: Evaluation, Management and Policy. A.S. Alsharhan and W.W. Wood, eds., pp. 53-62. Amsterdam, The Netherlands: Elsevier Science, 2003.

Williams, J.R., V. Lewelyn, D. DeLano, and I. Thangavelu. “Irrigation Cost Estimation Procedures Used in the Irrigation Economics Evaluation System (IEES.)” Research Report 23, Department of Agricultural Economics, Kansas State University, 1996.

Williams, J.R., R.V. Llewelyn, M.S. Reed, F.R. Lamm, and D.R. DeLano. “Economic Analysis of Alternative Irrigation Systems for Continuous Corn and Grain Sorghum in Western Kansas.” Report of Progress 766, Agricultural Experiment Station, Kansas State University, May 1997.

Yaron, D., E. Bresler, H. Bielorai, and B. Harpinist. “A Model for Optimal Irrigation Scheduling with Saline Water.” Water Resources Research 16(1980):257-62. 
Table 1. Three-Stage Parameter Estimates for the Just-Pope Model ${ }^{a}$

\section{Equation}

\begin{tabular}{|c|c|c|}
\hline Variable & Expected Yield & Standard Deviation of Yield \\
\hline \multirow[t]{2}{*}{ Intercept } & 17.49986 & 4.283024 \\
\hline & $(50.85)$ & $(1.55)$ \\
\hline \multirow[t]{2}{*}{$\ln w_{1}$} & & 1.040318 \\
\hline & & (1.14) \\
\hline \multirow[t]{2}{*}{$\ln w_{2}$} & & -2.39933 \\
\hline & & $(-2.58)$ \\
\hline \multirow[t]{2}{*}{$\ln w_{3}$} & 0.311982 & 4.45176 \\
\hline & $(6.90)$ & (3.29) \\
\hline \multirow[t]{2}{*}{$\ln w_{4}$} & 0.304174 & -3.99008 \\
\hline & $(12.04)$ & $(-3.42)$ \\
\hline \multirow[t]{2}{*}{$\left(\ln w_{1}\right)^{2}$} & -0.07161 & \\
\hline & $(-8.07)$ & \\
\hline \multirow[t]{2}{*}{$\left(\ln w_{2}\right)^{2}$} & 0.157869 & \\
\hline & $(4.31)$ & \\
\hline \multirow[t]{2}{*}{$\left(\ln w_{3}\right)^{2}$} & & -0.8574 \\
\hline & & $(-2.82)$ \\
\hline
\end{tabular}




\begin{tabular}{|c|c|c|}
\hline$\left(\ln w_{4}\right)^{2}$ & 0.172235 & \\
\hline & (7.93) & \\
\hline$\left(\ln w_{1}\right)\left(\ln w_{3}\right)$ & 0.132489 & -0.87966 \\
\hline & (3.03) & $(-2.33)$ \\
\hline$\left(\ln w_{1}\right)\left(\ln w_{4}\right)$ & & 0.416755 \\
\hline & & (1.55) \\
\hline$\left(\ln w_{2}\right)\left(\ln w_{3}\right)$ & -0.30639 & \\
\hline & $(-6.97)$ & \\
\hline$\left(\ln w_{2}\right)\left(\ln w_{4}\right)$ & -0.06394 & 1.361203 \\
\hline & $(-1.35)$ & (3.14) \\
\hline$\left(\ln w_{3}\right)\left(\ln w_{4}\right)$ & -0.1339 & \\
\hline & $(-3.73)$ & \\
\hline Adjusted $R^{2}$ & 0.89 & 0.08 \\
\hline Observations & 240 & 240 \\
\hline
\end{tabular}

\footnotetext{
${ }^{a}$ t-ratios in parentheses.
} 
Table 2. Elasticities at the Data Means and Extremes

\begin{tabular}{|c|c|c|c|c|c|c|}
\hline \multirow[b]{2}{*}{ Water Use Variable } & \multicolumn{3}{|c|}{ Expected Yield } & \multicolumn{3}{|c|}{ Standard Deviation of Yield } \\
\hline & Min & Mean & Max & Min & Mean & Max \\
\hline Preplant $\left(w_{1}\right)$ & 0.467 & 0.034 & -0.158 & 0.092 & 0.092 & 0.092 \\
\hline Vegetative $\left(w_{2}\right)$ & -0.052 & 0.153 & 0.202 & 0.592 & 0.592 & 0.592 \\
\hline Flowering $\left(w_{3}\right)$ & 0.409 & 0.025 & -0.105 & 2.624 & -0.293 & -1.281 \\
\hline Ripening $\left(w_{4}\right)$ & 0.033 & 0.033 & 0.033 & -0.070 & -0.070 & -0.070 \\
\hline
\end{tabular}


Table 3. Model Parameters

\begin{tabular}{|c|c|}
\hline Parameter & Value(s) \\
\hline Risk aversion coefficient $(a)$ & $0,0.03$ \\
\hline Well capacity (gallons per minute) & 300,500 \\
\hline Corn price (\$/bushel) & 2.28 \\
\hline Non-water variable costs (\$/acre) ${ }^{a}$ & 172.13 \\
\hline \multicolumn{2}{|l|}{ Cost of irrigation capital (\$/acre) } \\
\hline Flood & 41.06 \\
\hline Center pivot sprinkler & 73.84 \\
\hline Subsurface drip & 118.93 \\
\hline \multicolumn{2}{|l|}{ Application efficiency } \\
\hline Flood & 0.6 \\
\hline Center pivot sprinkler & 0.75 \\
\hline Subsurface drip & 1.0 \\
\hline \multicolumn{2}{|c|}{ Marginal pumping costs at 300, 500 gpm (\$/inch) } \\
\hline Flood & $2.15,1.91$ \\
\hline Center pivot sprinkler & 2.93, 2.61 \\
\hline Subsurface drip & $2.68,2.44$ \\
\hline
\end{tabular}

\footnotetext{
${ }^{a}$ Includes expenses for seed, pesticides, fertilizer, crop consulting, and interest on one-half of variable costs.
} 
Table 4. Irrigation Constraints and Constrained Optimal Irrigation Schedules ${ }^{a}$

\begin{tabular}{|c|c|c|c|c|c|c|}
\hline \multirow[b]{2}{*}{ Item } & \multicolumn{3}{|c|}{300 gpm Well Capacity } & \multicolumn{3}{|c|}{500 gpm Well Capacity } \\
\hline & Flood & Sprinkler & Drip & Flood & Sprinkler & Drip \\
\hline \multicolumn{7}{|c|}{ 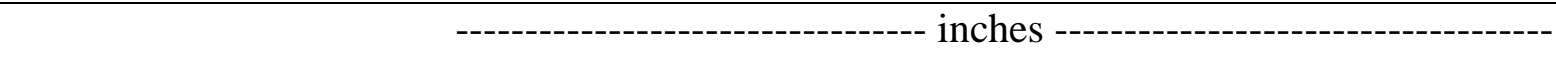 } \\
\hline \multicolumn{7}{|c|}{ Irrigation Constraint Limits } \\
\hline Preplant & 4.57 & 5.80 & 4.57 & 7.62 & 9.67 & 7.61 \\
\hline Vegatative & 5.96 & 7.57 & 5.96 & 9.93 & 12.61 & 9.93 \\
\hline Flowering & 1.99 & 2.52 & 1.99 & 3.31 & 4.21 & 3.31 \\
\hline Ripening & 4.97 & 6.31 & 4.97 & 8.28 & 10.51 & 8.28 \\
\hline Season total & 24.00 & 24.00 & 24.00 & 24.00 & 24.00 & 24.00 \\
\hline
\end{tabular}

Optimal Irrigation Amounts, Risk Neutrality $(a=0)$

$\begin{array}{lrrrrrr}\text { Preplant } & 3.25 & 2.89 & 2.35 & 3.04 & 2.17 & 2.25 \\ \text { Vegatative } & 5.96 & 7.57 & 5.96 & 9.59 & 11.10 & 9.93 \\ \text { Flowering } & 1.99 & 2.52 & 1.98 & 3.29 & 3.74 & 2.46 \\ \text { Ripening } & 4.97 & 6.31 & 4.97 & 7.68 & 6.99 & 8.26 \\ \text { Season total } & 16.16 & 19.28 & 15.26 & 23.59 & 24.00 & 22.91\end{array}$

Optimal Irrigation Amounts, Risk Aversion $(a=0.03)$

$\begin{array}{lrrrrrr}\text { Preplant } & 2.37 & 1.90 & 1.49 & 2.20 & 1.74 & 1.47 \\ \text { Vegatative } & 5.96 & 7.49 & 5.96 & 9.54 & 7.51 & 9.50 \\ \text { Flowering } & 1.99 & 2.37 & 1.84 & 3.11 & 3.33 & 1.82 \\ \text { Ripening } & 4.97 & 6.31 & 4.97 & 8.28 & 10.45 & 7.87 \\ \text { Season total } & 15.28 & 18.07 & 14.26 & 23.12 & 23.03 & 20.66\end{array}$

\footnotetext{
${ }^{a}$ Flood and drip systems irrigate 160 acres; a sprinkler system irrigates 126 acres.
} 
Table 5. Inputs, Output, and Net Returns, By Well Capacity and System Type ${ }^{a}$

\begin{tabular}{|c|c|c|c|c|c|c|}
\hline \multirow[b]{2}{*}{ Item } & \multicolumn{3}{|c|}{300 gpm Well Capacity } & \multicolumn{3}{|c|}{500 gpm Well Capacity } \\
\hline & Flood & Sprinkler & Drip & Flood & Sprinkler & Drip \\
\hline Total seasonal irrigation (inches) & 16.16 & 19.29 & 15.26 & 23.59 & 24.00 & 22.91 \\
\hline Water volume pumped (acre feet) & 215.47 & 202.49 & 203.51 & 314.53 & 252.00 & 305.47 \\
\hline Yield (bushels/acre) & 118.32 & 146.87 & 150.35 & 147.15 & 167.58 & 183.37 \\
\hline Pumping cost (\$/acre) & 34.74 & 56.51 & 40.90 & 45.06 & 62.64 & 55.90 \\
\hline Net return (\$/acre) ${ }^{d}$ & 21.83 & 36.17 & 10.83 & 77.25 & 77.26 & 71.12 \\
\hline Expected utility & 21.83 & 36.17 & 10.83 & 77.25 & 77.26 & 71.12 \\
\hline Expected utility, 30\% cost share ${ }^{e}$ & 21.83 & 36.17 & 46.51 & 77.25 & 77.26 & 106.80 \\
\hline
\end{tabular}


Risk Aversion $(a=0.03)$

\begin{tabular}{|c|c|c|c|c|c|c|}
\hline Total seasonal irrigation (inches) & 15.28 & 18.07 & 14.26 & 23.12 & 23.03 & 20.66 \\
\hline Total seasonal effective water (in) & 20.92 & 25.30 & 26.01 & 25.62 & 29.02 & 32.41 \\
\hline Water volume pumped (acre feet) & 203.73 & 189.72 & 190.19 & 308.27 & 241.82 & 275.47 \\
\hline Yield (bushels/acre) & 116.40 & 143.83 & 147.51 & 145.67 & 161.27 & 174.15 \\
\hline Pumping cost (\$/acre) & 32.85 & 52.94 & 38.23 & 44.16 & 60.11 & 50.41 \\
\hline Return to land and capital (\$/acre) $)^{b}$ & 60.41 & 106.65 & 125.97 & 115.84 & 139.24 & 174.52 \\
\hline Standard deviation $(\$ / \text { acre })^{c}$ & 88.11 & 87.54 & 90.1 & 86.72 & 77.73 & 87.90 \\
\hline Net return (\$/acre)d & 19.35 & 32.81 & 7.04 & 74.78 & 65.40 & 55.59 \\
\hline Expected utility & -97.10 & -82.14 & -114.73 & -38.03 & -25.23 & -60.30 \\
\hline Expected utility, 30\% cost share ${ }^{e}$ & -97.10 & -82.14 & -79.05 & -38.03 & -25.23 & -24.63 \\
\hline
\end{tabular}

${ }^{a}$ All measures are the arithmetic average over the states of nature 1985-2000. ${ }^{b}$ Revenue less variable costs.

${ }^{c} \sum_{s} S^{-1} \sigma_{s}\left(\mathbf{x}_{s}(\cdot)\right)$ in equation (15). $\quad{ }^{d} \sum_{s} S^{-1} \mu_{s}\left(\mathbf{x}_{s}(\cdot)\right)$ in equation (15). $\quad{ }^{e} 30 \%$ reduction in investment costs for subsurface drip. 